\title{
openheart Characteristics of anatomical difficulty for cryoballoon ablation: insights from CT
}

\author{
Takahiro Hayashi (D , , ${ }^{1,2}$ Masato Murakami, ${ }^{2}$ Shigeru Saito, ${ }^{2}$ Kiyotaka Iwasaki ${ }^{1}$
}

To cite: Hayashi T, Murakami M, Saito $\mathrm{S}$, et al. Characteristics of anatomical difficulty for cryoballoon ablation: insights from CT. Open Heart 2022;9:e001724. doi:10.1136/ openhrt-2021-001724

Received 19 May 2021 Accepted 29 November 2021

Check for updates

(c) Author(s) (or their employer(s)) 2022. Re-use permitted under CC BY-NC. No commercial re-use. See rights and permissions. Published by BMJ.

${ }^{1}$ Cooperative Major in Advanced Biomedical Sciences, Joint Graduate School of Tokyo Women's Medical University and Waseda University, Waseda University, Shinjuku-ku, Tokyo, Japan

2Department of Cardiology, Shonan Kamakura General Hospital, Kamakura, Kanagawa, Japan

\section{Correspondence to}

Professor Kiyotaka Iwasaki; iwasaki@waseda.jp

\section{ABSTRACT}

Background The limited availability of balloon sizes for cryoballoon leads to anatomical limitations for pulmonary vein $(\mathrm{PV})$ isolation. We conducted a comprehensive systematic analysis on procedural success rate, atrial fibrillation (AF) recurrence rate and complications of cryoballoon ablation in association with the anatomy of the left atrium and PV based on preprocedural CT to gain insights into proper treatments of patients with AF using cryoballoon.

Method A systematic search of literature databases, including PubMed, Web of Science and Cochrane Library, from the inception of each database through February 2021 was conducted. Search keywords included 'atrial fibrillation', 'cryoballoon ablation' and 'anatomy'. Results Overall, 243 articles were identified. After screening, 16 articles comprising 1396 patients were included (3, 5 and 8 for acute success, AF recurrence and complications, respectively). Regarding acute success and $A F$ recurrences, thinner width of the left lateral ridge, higher PV ovality, PV ostium-bifurcation distance, shorter distance from the non-coronary cusp to inferior PVs, shallower angle of right PVs against the atrial septum and larger right superior PV (RSPV) were associated with poor outcomes. Regarding complications, shorter distance between the RSPV ostium and the right phrenic nerve, larger RSPV-left atrium angle, larger RSPV area and smaller right carina width were associated with incidences of phrenic nerve injury.

Conclusion This study elucidated several key anatomical features of PVs possibly affecting acute success, $A F$ recurrence and complications in patients with $A F$ using cryoballoon ablation. CT analysis has helped to describe benefits and anatomical limitations for cryoballoon ablation.

\section{INTRODUCTION}

Catheter ablation is an established method for the treatment of patients with atrial fibrillation (AF), and pulmonary vein isolation (PVI) is an effective treatment strategy for paroxysmal AF (PAF). ${ }^{12}$ Since the release of the first-generation cryoballoon (Arctic Front, Medtronic, Minneapolis, Minnesota) in 2010 in the USA, data from both single-centre and multicentre studies have shown acute success and freedom from AF for 3 years. Event rates

\section{Key questions}

What is already known about this subject?

- Cryoballoon ablation is an established method for pulmonary vein $(\mathrm{PV})$ isolation.

- Preprocedural imaging is useful for the assessment of PV anatomy.

- Several reports have described acute success, atrial fibrillation (AF) recurrence and complications after cryoballoon ablation based on the PV anatomy using CT.

- However, the association between anatomy and safety or efficacy of cryoballoon ablation has not been well elucidated.

What does this study add?

- This study elucidated several key anatomical features of PVs that might affect acute success, AF recurrence and complications in the treatment of patients with AF using cryoballoon ablation.

How might this impact on clinical practice?

- The CT analysis have helped to describe limitations and benefits of cryoballoon ablation and they identified potential strategies to cope with the challenges.

of AF recurrences after cryoballoon ablation are reported to be comparable to those after radiofrequency ablation. ${ }^{3-6}$ However, there are only two balloon sizes for the cryoballoon (23 $\mathrm{mm}$ and $28 \mathrm{~mm}$ ), which leads to anatomical limitations for PVI. Preprocedural imaging is useful for the assessment of pulmonary vein (PV) anatomy. Several reports have described acute success, AF recurrence and complications after cryoballoon ablation based on the PV anatomy using CT. However, the association between anatomy and safety or efficacy of cryoballoon ablation has not been well elucidated. We conducted a comprehensive systematic analysis of procedural success rate, AF recurrence rate and complications of cryoballoon ablation in association with the anatomy of the left atrium and PV based on preprocedural CT to gain insights into proper treatments of patients with AF using cryoballoon. 


\section{MATERIALS AND METHODS}

\section{Data sources and search strategies}

A systematic search of electronic databases, including PubMed, Web of Science and Cochrane Library, from the inception of each database through February 2021 was conducted by two independent researchers ( $\mathrm{TH}$ and $\mathrm{KI}$ ) to identify relevant articles. Search keywords included 'atrial fibrillation', 'cryoballoon ablation' and 'anatomy'.

\section{Study selection}

The criteria for inclusion were as follows: (a) studies of patients with AF undergoing cryoballoon ablation and (b) studies reporting the safety and efficacy of anatomical predictors based on CT, including procedural success rate, $\mathrm{AF}$ recurrence rate (at least 1-year follow-up) and complications (phrenic nerve injury, oesophageal injury, PV stenosis and bronchial damage). Procedural success was defined as PVI with cryoballoon ablation. Studies were excluded if the published paper was a review, case report or animal study. Studies using the first-generation cryoballoon (Arctic Front) were excluded because the second-generation cryoballoon (Arctic Front Advance, Medtronic, Minneapolis, Minnesota, USA) is significantly better than the first-generation cryoballoon. Studies written in languages other than English were excluded. In the assessment of each study, any disagreement was resolved after a mutual consensus was reached (between TH and KI).

\section{RESULTS}

\section{Data included for comprehensive analysis}

One hundred and seventy-nine articles were initially identified from the literature search, and no additional

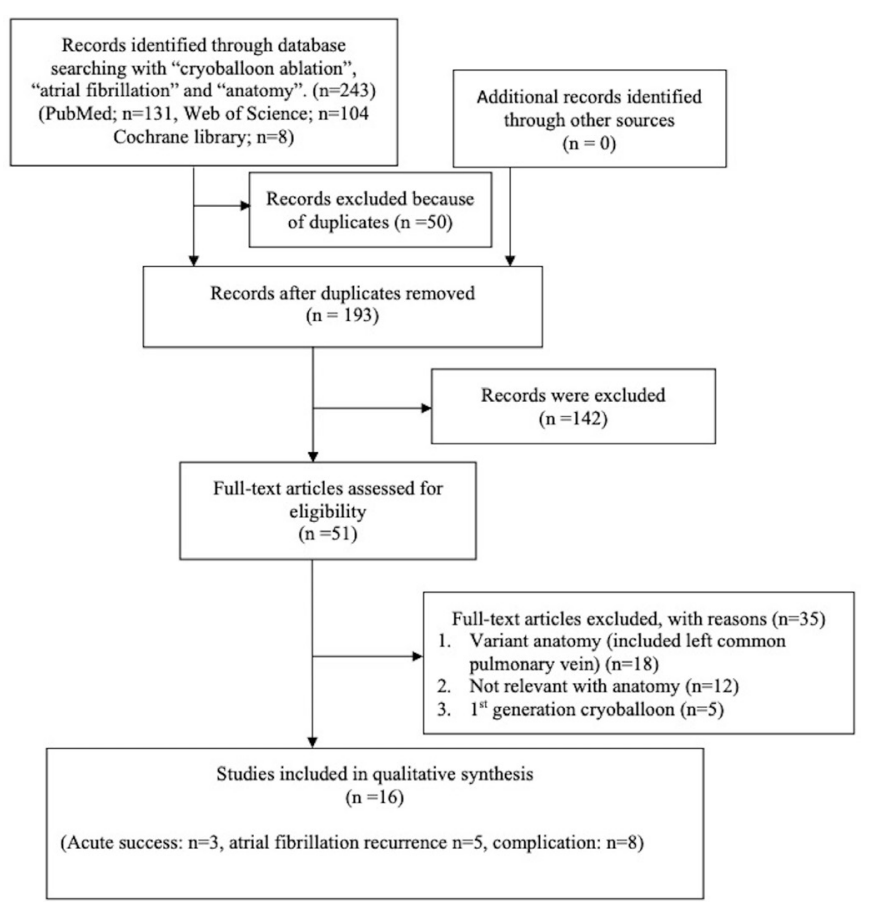

Figure 1 Literature search and study selection process in the systematic analysis. studies were included from other reports. Figure 1 shows a flow chart of the study. Twenty-nine duplicate articles from the three databases were excluded. After the titles and abstracts of these studies were screened, 51 were retrieved for full-text review. Of these, 35 studies were related to other topics and excluded. Five articles were related to the first-generation cryoballoon. The remaining 16 studies comprising 15 cohort studies, and 1 case-control study met the inclusion criteria. All studies were single-centre studies, and the second-generation cryoballoon was used in all of these studies (table 1). The studies included in the analysis comprised a total of 1396 patients, with sample sizes between 30 and 163. Overall, $974(69.8 \%)$ male patients were enrolled. The PAF ratio was $1257(90.0 \%)$. The follow-up periods for AF recurrence in the analysis ranged from 12 to 36 months.

\section{Anatomical predictors of acute success}

Regarding the acute success of cryoballoon ablation in patients with AF, three articles included anatomical investigations (table 2).

\section{Left superior pulmonary vein}

Kajiyama et al reported that a thinner left lateral ridge $(<4.7 \mathrm{~mm}) \quad(\mathrm{OR}=4.86,95 \%$ CI 1.43 to $16.50, \mathrm{p}=0.011)$, higher ovality index $(>50.5 \%)(\mathrm{OR}=9.44,95 \%$ CI 2.19 to 40.7, $\mathrm{p}=0.003$ ) and longer PV ostium-bifurcation distance $(>26.1 \mathrm{~mm}) \quad(\mathrm{OR}=5.98,95 \%$ CI 1.65 to $21.7, \mathrm{p}=0.006)$ required multiple applications of the cryoballoon to obtain a successful left superior $\mathrm{PVI}^{7}$ (figure 2A,B).

The ovality index of the PV was defined as $2 \times$ (major diameter-minor diameter)/(major diameter+minor diameter).

\section{Left inferior pulmonary vein}

Yasuoka et al reported that the height of the left inferior pulmonary vein (LIPV), which was defined as the distance from the base of the non-coronary cusp of the aorta to the bottom of the LIPV, might be a predictor of acute success. A distance from the non-coronary cusp to the LIPV of $<16.8 \mathrm{~mm}$ was related to the difficulty in LIPV isolation (OR=5.78, 95\% CI -1.77095 to -0.09474 , $\mathrm{p}=0.027)^{8}$

\section{Right superior pulmonary vein}

Matsumoto et al reported that right superior pulmonary vein (RSPV) angle was a predictor of procedural success. They reported the cut-off value for the RSPV angle against the line from the atrial septum to the left PV (LPV) (details are shown in figure 3A-F).${ }^{9}$ Shallower angle of RSPV against the atrial septum was associated with a poor outcome of acute success. The cut-off value for the RSPV angle of incomplete cryoballoon ablation was $<79.7^{\circ}$.

\section{Right inferior pulmonary vein}

Kajiyama et al reported that shorter PV ostium-bifurcation distance required multiple procedures $(<10.4 \mathrm{~mm})$ (figure $4 \mathrm{~A}) .{ }^{7}$ Yasuoka et al reported that right inferior 
Table 1 Articles included for comprehensive analysis

(A) Acute success

\begin{tabular}{|c|c|c|c|c|c|c|c|c|}
\hline Study & $\mathbf{N}$ & PAF, n (\%) & $\begin{array}{l}\text { LA size, mean } \\
(\mathrm{mm}) \pm \mathrm{SD}\end{array}$ & $\begin{array}{l}\text { LVEF, mean } \\
(\%) \pm S D\end{array}$ & $\begin{array}{l}\text { Acute success of } \\
\text { LSPV }\end{array}$ & $\begin{array}{l}\text { Acute } \\
\text { success } \\
\text { of LIPV }\end{array}$ & $\begin{array}{l}\text { Acute } \\
\text { success of } \\
\text { RSPV }\end{array}$ & $\begin{array}{l}\text { Acute success } \\
\text { of RIPV }\end{array}$ \\
\hline $\begin{array}{l}\text { Kajiyama } \\
\text { et al }\end{array}$ & 110 & $110(100)$ & $37.7 \pm 5.3$ & $66.2 \pm 7.1$ & $\begin{array}{l}95 \% \\
(102 / 107)\end{array}$ & $\begin{array}{l}92.4 \% \\
(98 / 106)\end{array}$ & $96.8(92 / 95)$ & $\begin{array}{l}85 \% \\
(85 / 100)\end{array}$ \\
\hline Yasuoka et $a^{\beta}$ & 30 & $30(100)$ & $40 \pm 5$ & $67 \pm 7$ & - & $\begin{array}{l}93.3 \% \\
(28 / 30)\end{array}$ & - & $\begin{array}{l}76.7 \% \\
(23 / 30)\end{array}$ \\
\hline $\begin{array}{l}\text { Matsumoto } \\
\text { et a }{ }^{\rho}\end{array}$ & 100 & $78(78)$ & $\begin{array}{l}37.0 \\
(24.2-49.4)\end{array}$ & $\begin{array}{l}66.7 \\
(52.4-78.3)\end{array}$ & $\begin{array}{l}96 \% \\
(96 / 100)\end{array}$ & $\begin{array}{l}100 \% \\
(100 / 100)\end{array}$ & $\begin{array}{l}92 \% \\
(92 / 100)\end{array}$ & $\begin{array}{l}80 \% \\
(80 / 100)\end{array}$ \\
\hline \multicolumn{9}{|c|}{ (B) AF recurrence } \\
\hline Study & $\mathbf{N}$ & PAF, n (\%) & $\begin{array}{l}\text { LA size, mean } \\
(\mathrm{mm}) \pm \mathrm{SD}\end{array}$ & $\begin{array}{l}\text { LVEF mean } \\
(\%) \pm S D\end{array}$ & Duration of AF & \multicolumn{2}{|c|}{ Follow-up period } & $\begin{array}{l}\text { Outcomes } \\
\text { (AF recurrence) }\end{array}$ \\
\hline Güler et al ${ }^{11}$ & 54 & $30(55.6)$ & $35.4 \pm 4.5$ & $63 \pm 2$ & 19 (3-60) months & \multicolumn{2}{|c|}{ At 12 months } & $20.4 \%(11 / 54)$ \\
\hline $\begin{array}{l}\text { Kocyigit et } \\
\text { all }^{10}\end{array}$ & 160 & $108(67.5)$ & & $63.6 \pm 2.9$ & - & \multicolumn{2}{|c|}{17 (12-36) months } & $24.3 \%(39 / 160)$ \\
\hline Mulder et al ${ }^{14}$ & 88 & $88(100)$ & $31 \pm 7$ & $57 \pm 2$ & $2.9(1.2-6.6)$ years & \multicolumn{2}{|c|}{ At 12 months } & $16.7 \%(14 / 84)$ \\
\hline $\begin{array}{l}\text { Terasawa et } \\
\text { al }^{12}\end{array}$ & 129 & $85(66)$ & $43 \pm 7$ & $57 \pm 7$ & - & \multicolumn{2}{|c|}{$18 \pm 14$ months } & - \\
\hline $\begin{array}{l}\text { Vaishnav et } \\
a l^{13}\end{array}$ & 58 & $35(60.3)$ & $41.2+7.7$ & $54.16+8.09$ & - & \multicolumn{2}{|c|}{ At 12 months } & $\begin{array}{l}65.5 \% \\
(38 / 58)\end{array}$ \\
\hline \multicolumn{9}{|c|}{ (C) Complication } \\
\hline Study & $\mathbf{N}$ & \multicolumn{2}{|l|}{ PAF, n (\%) } & \multicolumn{2}{|c|}{ LA size, mean $(\mathrm{mm}) \pm S D$} & & \multicolumn{2}{|l|}{ Outcomes } \\
\hline $\begin{array}{l}\text { Ichihara et } \\
\left.a\right|^{15}\end{array}$ & 100 & \multicolumn{2}{|l|}{$100(100)$} & \multicolumn{2}{|l|}{$37.9 \pm 5.3$} & & \multicolumn{2}{|l|}{ PNI (9\%: 9/100) } \\
\hline Ströker et al ${ }^{16}$ & 163 & \multicolumn{2}{|c|}{$\begin{array}{l}31(76) \text { at PNI group, } \\
106 \text { (86) at no PNI group }\end{array}$} & \multicolumn{2}{|c|}{$\begin{array}{l}40.4 \pm 7 \text { at PNI group } \\
39.6 \pm 7 \text { at no PNI group }\end{array}$} & & \multicolumn{2}{|c|}{ PNI (37\%: 41/164) } \\
\hline Maj et $a l^{17}$ & 90 & \multicolumn{2}{|c|}{$\begin{array}{l}30(93.8) \text { at group 1, } \\
17(73.9) \text { at group 2, } \\
30 \text { (85.7) at group 3 }\end{array}$} & \multicolumn{2}{|c|}{$\begin{array}{l}41.4 \pm 6.8 \text { at group } 1 \\
39.7 \pm 10.2 \text { at group } 2 \\
41.8 \pm 5.7 \text { at group } 3\end{array}$} & & \multicolumn{2}{|l|}{ PNI (2.1\%) } \\
\hline $\begin{array}{l}\text { Miyazaki et } \\
\text { al }\end{array}$ & 40 & \multicolumn{2}{|l|}{$40(100)$} & \multicolumn{3}{|l|}{$37.3 \pm 5.9$} & \multicolumn{2}{|c|}{ Oesophageal injury (32.5\%: 13/40) } \\
\hline $\begin{array}{l}\text { Matsumoto } \\
\text { et al }{ }^{19}\end{array}$ & 110 & \multicolumn{2}{|l|}{$105(95)$} & \multicolumn{3}{|l|}{$36.8 \pm 5.9$} & \multicolumn{2}{|c|}{$\begin{array}{l}\text { Oesophageal injury } \\
(17.3 \%: 19 / 110)\end{array}$} \\
\hline $\begin{array}{l}\text { Coutiño et } \\
\left.a\right|^{20}\end{array}$ & 74 & \multicolumn{2}{|l|}{$74(100)$} & \multicolumn{3}{|l|}{$36.1 \pm 4.5$} & \multicolumn{2}{|c|}{$\begin{array}{l}\text { Pulmonary vein stenosis } \\
\text { (severe stenosis 1.1\%: } 3 / 271 \mathrm{PV} \text { ) }\end{array}$} \\
\hline Narui et $a l^{11}$ & 54 & \multicolumn{2}{|l|}{$54(100)$} & \multicolumn{3}{|l|}{$37.2 \pm 4.4$} & \multicolumn{2}{|c|}{$\begin{array}{l}\text { Pulmonary vein stenosis } \\
\text { (none severe stenosis) }\end{array}$} \\
\hline Wei et $a^{22}$ & 90 & \multicolumn{2}{|c|}{$\begin{array}{l}25 \text { (83) at haemoptysis group } \\
51 \text { (85) at no haemoptysis group }\end{array}$} & \multicolumn{2}{|c|}{$\begin{array}{l}39.3 \pm 4.9 \text { at haemoptysis group } \\
40.4 \pm 5.2 \text { at no haemoptysis group }\end{array}$} & & $\begin{array}{l}\text { Haemoptysis } \\
(33.3 \%: 30 / 90)\end{array}$ & \\
\hline
\end{tabular}

AF, atrial fibrillation; LA, left atrium; LIPV, left inferior pulmonary vein; LSPV, left superior pulmonary vein; LVEF, left ventricular ejection fraction; PAF, paroxysmal atrial fibrillation; PNI, phrenic nerve injury; PV, pulmonary vein; RIPV, right inferior pulmonary vein; RSPV, right superior pulmonary vein; TS, transseptal.

pulmonary veins (RIPVs) are difficult to isolate. RIPV angle $<105^{\circ}$ against the vertical line at the transverse plane and RIPV position $<1.250 \mathrm{~mm}$ (the distance from the base of the non-coronary cusp of the aorta to the bottom of the RIPV) were independent factors for difficulty in RIPV isolation (RIPV angle: OR $=23.80,95 \%$ CI -3.15528 to $-0.53622, \mathrm{p}=0.002$; RIPV position: $\mathrm{OR}=12.14$, $95 \%$ CI -2.77301 to $-0.23160, p=0.014$ ) (figure $4 \mathrm{~B}, \mathrm{C}$ ). ${ }^{8}$ Matsumoto et al reported that the RIPV angle against the line from the atrial septum to the LPV was associated with acute success. The definition of the angle is similar to that shown in figure 3A-F. They reported that an RIPV angle $<40.1^{\circ}$ against the line from the atrial septum to the LPV was associated with a poor outcome of acute success (figure 3E). ${ }^{9}$

Figure 5 shows two typical cases from Shonan Kamakura General Hospital, and we measured RIPV position and RIPV angles. In case A, the RIPV was easy to isolate 


\begin{tabular}{|c|c|}
\hline Anatomy & CT analysis \\
\hline LSPV & $\begin{array}{l}\text { 1. Left lateral ridge }<4.7 \mathrm{~mm}, \mathrm{OR}(95 \% \mathrm{Cl}) 4.86(1.43 \text { to } 16.50), \mathrm{p}=0.011 .^{7} \\
\text { 2. Ovality } \geqq 50.5 \%, \mathrm{OR}(95 \% \mathrm{Cl}) 9.44(2.19 \text { to } 40.7), \mathrm{p}=0.003 .^{7} \\
\text { 3. PV ostium-bifurcation distance } \geqq 26.1 \mathrm{~mm}, \mathrm{OR}(95 \% \mathrm{Cl}) 5.98 \text { ( } 1.65 \text { to } 21.7), \mathrm{p}=0.006 .^{7}\end{array}$ \\
\hline LIPV & 1. Position from non-coronary cusp (<16.875 mm), OR (95\% Cl) $5.78(-1.77095$ to -0.09474$), p=0.027 .^{8}$ \\
\hline RSPV & 1. $\mathrm{PV}$ angle at vertical section, $\mathrm{OR}(95 \% \mathrm{Cl}) 1.17$ (1.09 to 1.27), $\mathrm{p}<0.0001 .^{9}$ \\
\hline RIPV & $\begin{array}{l}\text { 1. PV ostium-bifurcation distance } \leqq 10.4 \mathrm{~mm}, \mathrm{OR}(95 \% \mathrm{Cl}) 10.1(3.0 \text { to } 34.3), \mathrm{p}<0.001 .^{7} \\
\text { 2. } \mathrm{PV} \text { angle at cross section }\left(<105^{\circ}\right), \mathrm{OR}(95 \% \mathrm{Cl}) 23.80(-3.15528 \text { to }-0.53622), \mathrm{p}=0.002 .^{8} \\
\text { 3. PV position from non-coronary cusp }(<1.250 \mathrm{~mm}), \mathrm{OR}(95 \% \mathrm{Cl}) 12.14(-2.77301 \text { to }-0.23160), p=0.014 .^{8} \\
\text { 4. PV angle at vertical section, } \mathrm{OR}(95 \% \mathrm{Cl}): 1.12(1.01 \text { to } 1.23), p=0.0136 .^{9}\end{array}$ \\
\hline
\end{tabular}

LIPV, left inferior pulmonary vein; LSPV, left superior pulmonary vein; PV, pulmonary vein; RIPV, right inferior pulmonary vein; RSPV, right superior pulmonary vein.

(figure 5A-C). On the contrary, in case B, multiple applications of cryoballoon had to be performed for RIPV isolation (figure 5D-F). In case A, the distance from the base of a non-coronary cusp of the aorta to the bottom of the LIPV was $10.5 \mathrm{~mm}$ (figure 5A). The RIPV angle against the vertical line at the transverse plane was $121.6^{\circ}$ (figure 5B). The RIPV angle against the line from the atrial septum to the LPV at coronal image was $74.3^{\circ}$ (figure $5 \mathrm{C}$ ). In case $\mathrm{B}$, the distance from the base of a non-coronary cusp of the aorta to the bottom of the LIPV was $0.8 \mathrm{~mm}$ (figure 5D). The RIPV angle against the vertical line at the transverse plane was $104^{\circ}$ (figure 5E). The RIPV angle against the line from the atrial septum to the LPV at coronal images was $37.5^{\circ}$ (figure 5F).

Predictors of mid-term or long-term success of AF recurrence Regarding AF recurrence after cryoballoon ablation in patients with AF, five articles included anatomical investigations (table 3 ).

\section{Left superior pulmonary vein}

Regarding left superior pulmonary vein (LSPV), no study has reported the influence of LSPV on AF recurrence.

Left inferior pulmonary vein

Kocyigit et al reported that the caudal position of the LIPV was a predictor of AF recurrence. ${ }^{10}$ The median PV trunk
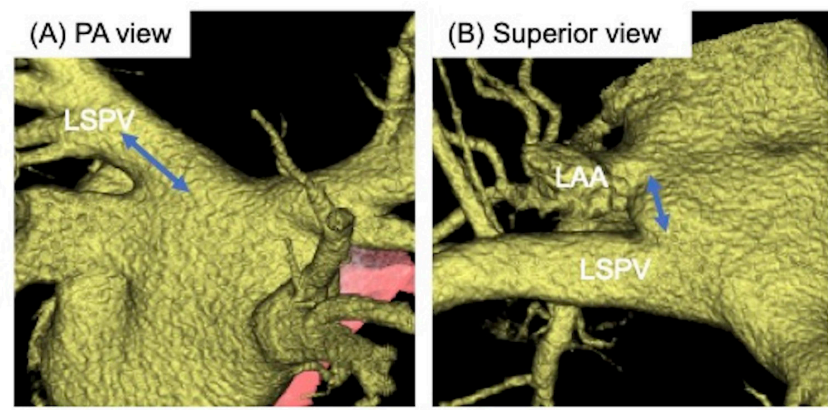

Figure 2 A CT analysis of the left superior pulmonary vein and left lateral ridge. (A) PA view: LSPV ostium-bifurcation distance. (B) Superior view: length of the left lateral ridge. LAA, left atrial appendage; LSPV, left superior pulmonary vein; PA, posterior-anterior. angle was calculated in the transverse and coronal planes of the PV trunk. Each PV trunk was assigned to one of the four orientation groups: ventral-caudal, dorsal-caudal, ventral-cranial and dorsal-cranial, as compared with the median angle of each PV. Patients with dorsal-caudal LIPV orientation had a higher incidence of AF recurrence than those with dorsal-cranial orientation (HR 3.447 , 95\% CI 1.180 to $10.070, p=0.024$ ). Furthermore, patients with ventral-caudal PV orientation had higher $\mathrm{AF}$ recurrence than those with dorsal-cranial orientation (HR 3.391, 95\% CI 1.088 to $10.571, \mathrm{p}=0.035$ ).

\section{Right superior pulmonary veinRSPV}

Güler et al reported that a larger RSPV was a predictor of AF recurrence. They reported that the mean diameter of RSPV in the AF recurrence group was $21.6 \pm 2.8 \mathrm{~mm} .{ }^{11}$
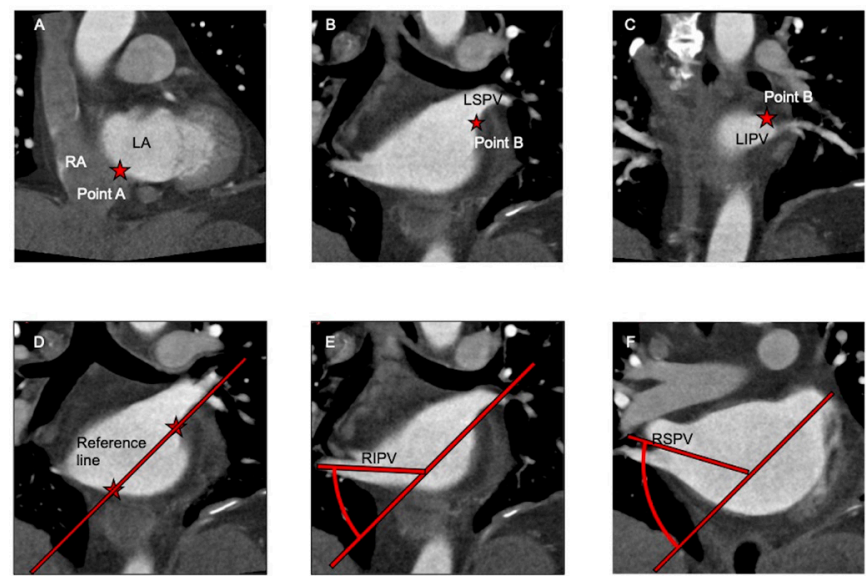

Figure 3 A process for measuring pulmonary vein angle. (A) A landmark (star) is placed on the centre of the atrial septum (point A). (B) and (C) Another landmark (star) is placed at the centre of the left PV from the bottom of the LSPV and the roof of the LIPV (point B). (D) The line connecting points $A$ and $B$ is the reference line. $(E)$ and (F) The angles of the RIPV and RSPV are obtained from the reference line and each PV ostium. LA, left atrium; LIPV, left inferior pulmonary vein; LSPV, left superior pulmonary vein; $\mathrm{RA}$, right atrium; RIPV, right inferior pulmonary vein; RSPV, right superior pulmonary vein. 

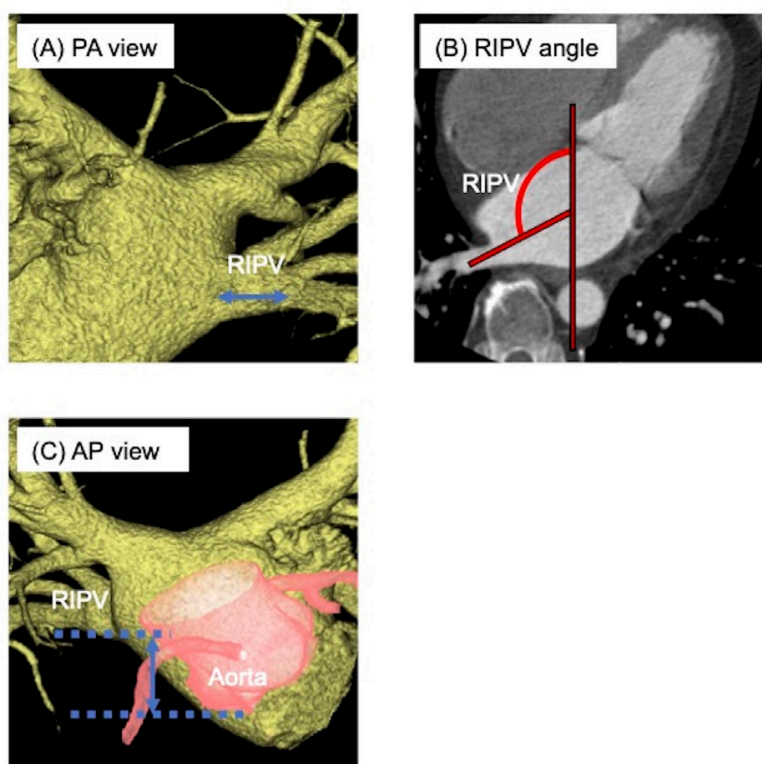

Figure 4 A CT analysis of the RIPV. (A) PA view: RIPV ostium-bifurcation distance. (B) RIPV angle against the vertical line at the transverse plane. (C) AP view: the distance from the non-coronary cusp to the RIPV. AP, anterior-posterior; PA, posterior-anterior; RIPV, right inferior pulmonary vein.

\section{Right superior pulmonary vein}

Terasawa et al reported that RIPV angle against the atrial septum at the coronal view was a predictor of $\mathrm{AF}$ recurrence (OR 1.13, 95\% CI 1.07 to $1.19, \mathrm{p}<0.001) .{ }^{12} \mathrm{~A}$ shallower angle against the atrial septum in the coronal view was associated with a higher incidence of AF recurrence.

Prediction of unfavourable left atrium-PV anatomy for cryoballoon ablation

One article showed a score for predicting unfavourable left atrium and PV anatomy. ${ }^{13}$ The score consists of seven factors: (1) RSPV ovality index $>1.32$; (2) LSPV ovality index $>1.2$; (3) RSPV antral circumference $>69.1 \mathrm{~mm}$; (4) RIPV antral circumference $>61.38 \mathrm{~mm}$; (5) RSPV $>22.7^{\circ}$, which was defined as the angle from the horizontal line to the RSPV on the coronal view; (6) left atrium diameter $>43.5 \mathrm{~mm}$ and (7) presence of the right middle PV. They reported that patients with scores $\geq 4$ required longer cryoapplication times $(\mathrm{p}=0.002)$ and more frequent switching to radiofrequency catheters $(p=0.066)$ to achieve PVI than those with scores $<4$. Patients with scores $\geq 4$ showed a trend towards more cryoapplications $(\mathrm{p}=0.059)$ and longer total procedural times $(\mathrm{p}=0.068)$ than those with scores $<4$.

\section{Articles reporting no association between anatomy and AF recurrence}

One study reported that PV anatomy was not associated with AF recurrence. Mulder et al reported an association between $\mathrm{PV}$ anatomy and $\mathrm{AF}$ recurrence in 84 patients. They reported that neither PV ovality, variant anatomy
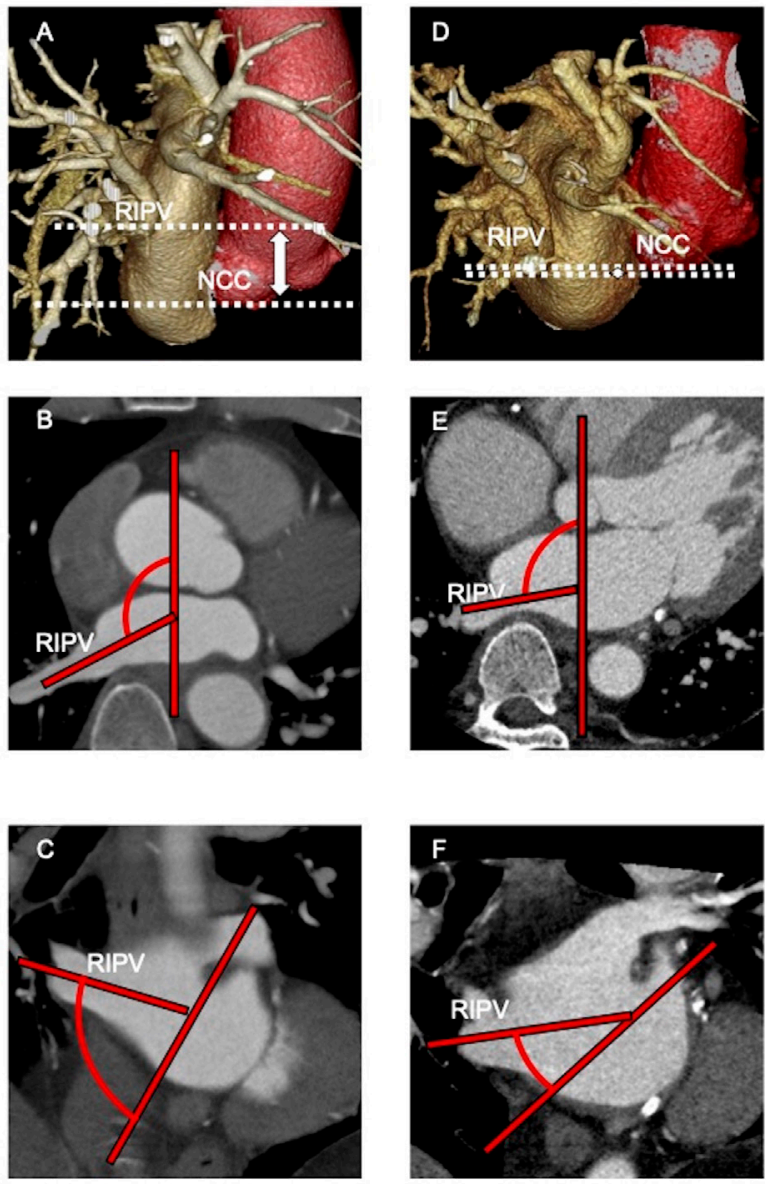

Figure 5 Typical two cases that we measured the RIPV position and RIPV angle. (A) The distance from the NCC to the RIPV of case A. One white dotted line represents the location of the bottom of the RIPV. The other white dotted line represents the location of the bottom of the NCC.

(B) RIPV angle against the vertical line at the transverse plane of case A. (C) RIPV angle against the line from the atrial septum to the LPV at the coronal image of case $A$. (D) The distance from the NCC to the RIPV of case B. One white dotted line represents the location of the bottom of the RIPV. The other white dotted line represents the location of bottom of the NCC. (E) RIPV angle against the vertical line at the transverse plane of case B. (F) RIPV angle against the line from the atrial septum to the left pulmonary vein at the coronal image of case B. NCC, non-coronary cusp; RIPV, right inferior pulmonary vein.

and the presence of shared carina nor a common LPV was a predictor of AF recurrence. ${ }^{14}$

\section{Complications}

Regarding complications of cryoballoon ablation in patients with AF, eight articles included anatomical investigations (table 4 ).

\section{Phrenic nerve injury}

Through our study, five reports discussed phrenic nerve injury.

Ichihara et al reported that the optimal cut-off point for the distance between the RSPV ostium and the right pericardiophrenic bundles for predicting right phrenic 
Table 3 Anatomic predictors of mid-term or long-term success about AF recurrence

\begin{tabular}{|c|c|}
\hline Anatomy & CT analysis \\
\hline LSPV & - \\
\hline LIPV & $\begin{array}{l}\text { 1. PV dorsal-caudal comparing to dorsal-cranial orientation (HR } 3.447,95 \% \mathrm{Cl} 1.180 \text { to } 10.070, \mathrm{p}=0.024) .{ }^{10} \\
\text { 2. } \mathrm{PV} \text { ventral-caudal to dorsal-cranial orientation (HR } 3.391,95 \% \mathrm{Cl} 1.088 \text { to } 10.571, \mathrm{p}=0.035) .{ }^{10}\end{array}$ \\
\hline RSPV & 1. RSPV diameter: $21.6 \pm 2.8 \mathrm{~mm}$ at AF recurrence group vs $15.8 \pm 2.1 \mathrm{~mm}$ at no $A F$ recurrence group $(p<0.001){ }^{11}$ \\
\hline RIPV & 1. RIPV-TS frontal angle $\left(^{\circ}\right): 45 \pm 17^{\circ}$ at persistent RIPV isolation group vs $30 \pm 14^{\circ}$ at RIPV reconnection group. ${ }^{12}$ \\
\hline $\begin{array}{l}\text { No association between anatomy and } \\
\text { AF recurrence }\end{array}$ & $\begin{array}{l}\text { 1. No relationship with anatomy (PV ovality, the presence of anatomical variants (right middle PVs, common ostia), shared } \\
\text { carina nor carina width). }{ }^{14} \text {. }\end{array}$ \\
\hline
\end{tabular}

AF, atrial fibrillation; LIPV, left inferior pulmonary vein; LSPV, left superior pulmonary vein; PV, pulmonary vein; RIPV, right inferior pulmonary vein; RSPV, right superior pulmonary vein.

nerve injury was $12.4 \mathrm{~mm}$ (sensitivity $96.6 \%$, specificity $88.9 \%$ ), with an area under the curve of 0.968 (95\% CI 0.922 to 1.000 ) (figure $6 \mathrm{~A}) .{ }^{15}$ Ströker et al reported that RSPV-left atrium angle $>141^{\circ}$, defined as the external angle between the RSPV and the right anterolateral wall of the LA on an axial image, along with the crosssectional line positioned at the ostium, was a predictor of phrenic nerve injury (91\% sensitivity, $85 \%$ specificity) (figure 6B). Furthermore, an RSPV area $>275 \mathrm{~mm}^{2}$ was also a predictor of phrenic nerve injury $(88 \%$ sensitivity, $85 \%$ specificity) ${ }^{16}$ Maj et al reported that the carina width was significantly smaller in patients with phrenic nerve injury occurring during both right-sided PV (RSPV and RIPV) cryoapplications than in patients who had phrenic nerve injury only during one right-sided PV application (either RSPV or RIPV) $(\mathrm{p}<0.0001)$, with a cut-off value of $8.5 \mathrm{~mm}$, sensitivity of $87.3 \%$ and specificity of $75.0 \%{ }^{17}$

\section{Oesophageal injury}

There were two reports related to oesophageal thermal lesions.

Miyazaki et al reported that the optimal cut-off point for the distance between the oesophagus and LIPV ostium for predicting no oesophageal thermal lesions was $2.0 \mathrm{~mm}$ (sensitivity $84.4 \%$, specificity $62.5 \%$ ), but the difference was not statistically significant $(\mathrm{p}=0.078)$ (figure 6C). ${ }^{18}$ Matsumoto et al reported that the left atrium-aorta distance in the horizontal view was an independent predictor of oesophageal thermal lesions (OR $0.430, p=0.013)$. The mean left atrium-aorta distance in the oesophageal thermal lesions group was $4.9 \pm 1.3 \mathrm{~mm}$ and that in the no oesophageal thermal lesions group was $5.8 \pm 1.6 \mathrm{~mm}(\mathrm{p}=0.03)$ (figure $6 \mathrm{D}){ }^{19}$

\section{Pulmonary vein stenosis}

Several reports mentioned that a larger PV ostium was independently associated with PV narrowing. ${ }^{20}{ }^{21}$ When we compare PVs with and without PV narrowing (size reduction of $\Delta \mathrm{PV} \geq 25 \%$ vs $\Delta \mathrm{PV}<25 \%$ ), which was calculated as 1-post-PV ostium area/pre-PV ostium area $\times 100$ $(\%)$, the PV size before the procedure was significantly larger in PVs with narrowing than in those without $\left(2.9 \pm 1.1\right.$ vs $\left.2.4 \pm 0.9 \mathrm{~cm}^{2}, \mathrm{p}<0.001\right) .{ }^{21}$

\section{Bronchial damage}

One article reported an association between bronchial damage and anatomy. Wei et al reported that left main bronchus-LSPV ostium distance was a predictor

\section{Table 4 Anatomical predictors of complications}

\begin{tabular}{|c|c|}
\hline Outcome & CT analysis \\
\hline Phrenic nerve injury & 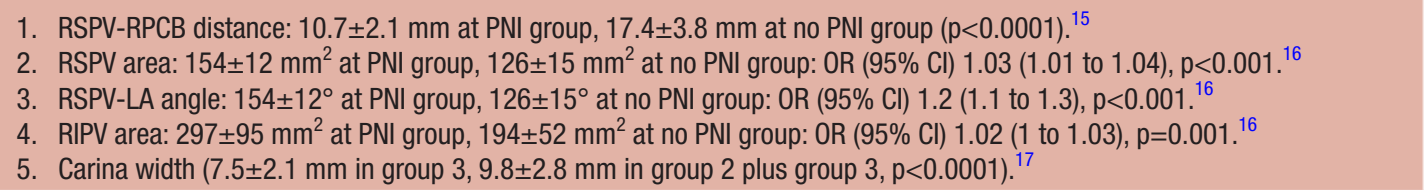 \\
\hline Oesophageal injury & $\begin{array}{l}\text { 1. The distance between oesophagus and LIPV ostium was not statistically different in two group }(3.5 \pm 3.3 \mathrm{~mm} \text { in injury }+ \text { group, } \\
8.1 \pm 7.0 \mathrm{~mm} \text { in injury - group, } \mathrm{p}=0.078) .^{18} \\
\text { 2. Left atrium-aorta distance (+1 SD increase) }(\mathrm{OR}(95 \% \mathrm{Cl}) 0.430(0.219 \text { to } 0.841), \mathrm{p}=0.013) .{ }^{19}\end{array}$ \\
\hline Pulmonary vein stenosis & $\begin{array}{l}\text { 1. A larger PV ostium }(\mathrm{OR}(95 \% \mathrm{Cl}) 1.773(1.137 \text { to } 2.765), \mathrm{p}=0.01){ }^{20} \\
\text { 2. A larger pulmonary vein ostium preprocedure diameter }(\mathrm{OR}(95 \% \mathrm{Cl}) 1.250(1.090 \text { to } 1.434), \mathrm{p}=0.001) .{ }^{21} \\
\text { 3. A larger pulmonary vein ostium preprocedure area }(\mathrm{OR}(95 \% \mathrm{Cl}) 1.006(1.002 \text { to } 1.011), \mathrm{p}=0.006) .{ }^{21}\end{array}$ \\
\hline Haemoptysis & 1. LMB-LSPV distance (OR (95\% Cl) 2.676 (1.121 to 4.843), $\mathrm{p}<0.001){ }^{22}$ \\
\hline
\end{tabular}

LMB, left main bronchus; PNI, phrenic nerve injury; PV, pulmonary vein; RIPV, right inferior pulmonary vein; RPCB, right peri-

cardiophrenic bundles; RSPV, right superior pulmonary vein. 

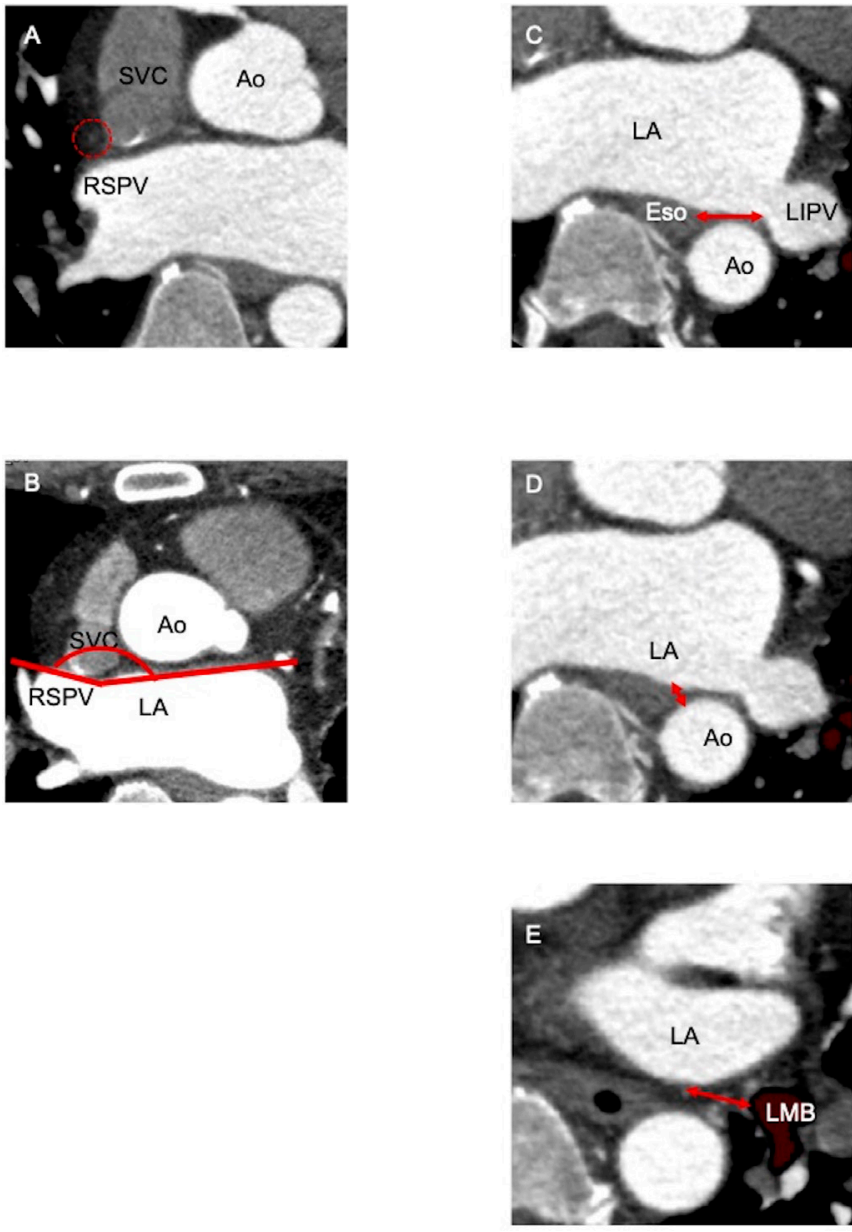

Figure 6 A CT analysis of anatomical predictors for complications. (A) The distance from the RSPV to the right phrenic nerve. The right phrenic nerve (red dotted circle) was identified on CT. (B) RSPV-LA angle. (C) Distance of the oesophagus and LIPV ostium. (D) Distance of the descending aorta and LA. (E) Distance of the left main bronchus and LSPV. Ao, aorta; Eso, oesophagus; LA, left atrium; LIPV, left inferior pulmonary vein; PA, posterior-anterior; PV, pulmonary vein; RSPV, right superior pulmonary vein.

of haemoptysis after cryoballoon ablation with a cut-off value of $\leq 9.5 \mathrm{~mm}$ and sensitivity and specificity of $93.8 \%$ and $75.0 \%$, respectively (figure $6 \mathrm{E}$ ). ${ }^{22}$

\section{DISCUSSION}

This study elucidated several key anatomical features of PVs that might affect acute success, AF recurrence and complications in the treatment of patients with $\mathrm{AF}$ using cryoballoon ablation. CT analysis was helpful to identify benefits and limitations of cryoballoon ablation in terms of anatomy.

\section{Anatomical factors of acute success and AF recurrence Left superior pulmonary vein}

Several articles reported the incidences of reconduction of PV isolation using cryoballoon for LSPV because the superior part of the LSPV specifically tended to reconnect. ${ }^{23242425}$ The LSPV generally exhibited an upright takeoff and a large trunk. However, catheter pushability might be impaired because of the longer distance from the interatrial septum. It is difficult to obtain sufficient pushability for oval and sharp ridges, which might be associated with the difficulty in PV isolation using the cryoballoon. In particular, the roof of the LSPV might be hard to cover with the balloon hemisphere even if the balloon and sheath have the correct force and direction.

\section{Left inferior pulmonary vein}

Regarding the incidence of reconduction of $\mathrm{PV}$ isolation after cryoballoon ablation for LIPV, the inferior part of the LIPV tended to reconnect. ${ }^{23-25}$ In addition to the LSPV, the distance from the septal is a problem. The inferior LIPV is a difficult target for achieving complete isolation with current cryoballoon technology because a bending sheath is necessary to hold the coaxial method.

\section{Right superior pulmonary vein}

Similar to LSPV, the superior part of RSPV tended to reconnect. ${ }^{23-25}$ This study showed that a shallower RSPV angle against the atrial septum was a predictor of acute success, and a larger RSPV was a predictor of AF recurrence. It may be difficult for the balloon hemisphere to touch the upper part of the RSPV in patients with a shallower RSPV angle.

\section{Right inferior pulmonary vein}

The bottom of the RIPV is the most difficult part to isolate, which is influenced by the distance between the atrial septum and RIPV. ${ }^{23-25}$ This study showed that a shorter PV distance is associated with lower acute success. In addition to LIPV, the inferior part of the RIPV tended to reconnect. ${ }^{23-25}$

In this study, a lower RIPV position from the noncoronary cusp and RIPV, which led to a sharp angle from the atrial septum, was associated with lower acute success. Lower RIPV and shorter distance of bifurcation were predictors of AF recurrence.

Advancing the cryoballoon catheter towards the ostium of the RIPV in anatomies with a lower RIPV position from the non-coronary cusp and RIPV, which has a sharp angle from the atrial septum, was regarded as difficult because physicians must create acute angulation with the stiff catheter. Furthermore, in cases with a shorter distance from the RIPV ostium to the RIPV first bifurcations, physicians may encounter difficulties in the stability and pushability of cryoballoon.

\section{Complications related to cryoballoon ablation}

\section{Phrenic nerve injury}

The prevalence of right phrenic nerve injury has been reported to be $11.2 \%$ due to various factors during cryoballoon ablation. ${ }^{3}$ The definition of phrenic nerve injury varies according to each paper. One definition of phrenic nerve injury is any perceived reduction in the strength of the diaphragmatic contractions or a significant reduction $(>30 \%)$ in the maximal diaphragmatic amplitude of compound motor action potential from baseline. ${ }^{15}$ The 
most common definition is that paralysis of the hemidiaphragm noted by both manual palpation and fluoroscopy during intraprocedural high-output pacing. The definition of transient phrenic nerve injury or persistent phrenic nerve injury is also variable. Another definition is that transient phrenic nerve injury completely resolved before the end of the procedure, while persistent phrenic nerve injury remained after the procedure. ${ }^{16}$ Matsumoto et al initially demonstrated the feasibility of using 64-slice multidetector CT for the detection and anatomic outline of the phrenic nerves and their relation to the cardiac anatomic structures. ${ }^{26}$ They showed that the distance from the RSPV to the phrenic nerve or area of the RSPV and the RSPV angle can be a predictor of phrenic nerve injury. Gentle sealing of the RSPV is technically important to prevent such complications during the procedure, and preprocedural risk stratification seems to help further reduce this complication.

\section{Oesophageal damage}

Oesophageal thermal lesions tend to be associated with a shorter distance from the oesophagus to the posterior left atrium. ${ }^{27}$ Oesophageal thermal lesions were defined as erythema, erosions (partial loss of the epithelial or mucosal surface) or ulcerations (full-thickness loss of the epithelial or mucosal surface) based on their macroscopic appearance..$^{28}$ Usually, the damage can be limited to oesophageal lesions, which frequently heal within a few weeks. The rate of atrial oesophageal fistula with firstgeneration cryoballoon and second-generation cryoballoon is reported to be approximately $0.01 \%$ (1:10 000), whereas the incidence of atrial oesophageal fistula with radiofrequency ablation varies between $0.1 \%$ (1:1000) and $0.25 \%(1: 400) .^{29}$

The distances from the oesophagus to the left atrium and from the left atrium to the descending aorta were predictors of oesophageal damage. Preprocedural examination of the distance from the oesophagus to the left atrium or the left atrium to the descending aorta is important.

\section{PV stenosis}

PV stenosis was classified into three groups according to the PV dimension reduction rate: mild stenosis $(25 \%-$ $50 \%)$, moderate stenosis $(50 \%-75 \%)$ and severe stenosis $(>75 \%) .{ }^{30}$ A previous study reported a $1.1 \%-3.1 \%$ incidence of severe PV stenosis $(>75 \%))^{3}{ }^{31}$ The mechanism of cellular damage due to freezing by cryoenergy has been shown to be a complex process with three primary factors: direct cellular damage, vascular failure and immunological effects. ${ }^{31}$ In this study, the size of the PV was found to be a predictor of PV stenosis. For larger PVs, radiofrequency ablation should be chosen to avoid PV stenosis.

\section{Bronchial damage}

There have been multiple reports of haemoptysis following cryoballoon ablation. ${ }^{32-34}$ Haemoptysis is considered a non-negligible complication. The mechanism of haemoptysis is considered to involve bronchi injury or PV stenosis. Clinically important haemoptysis was observed in $1.7 \%-5.6 \%$ of cases after cryoballoon ablation. ${ }^{223435}$ A clinical study of the the Sustained Treatment of Paroxysmal Fibrillation (STOP-AF) trial which is a randomised study comparing cryoballoon ablation and drug therapy found an incidence of persistent cough to be as high as $17 \%$ following ablation using the firstgeneration cryoballoon. ${ }^{3}$ Verma et al reported that realtime bronchoscopy was performed during cryoballoon ablation. They described that ice formation was visualised in the left main bronchus during cryoballoon ablation of the LSPV in $70 \%(7 / 10)$ of patients. ${ }^{32}$ From this systematic analysis, the left main bronchus-LSPV distance was a predictor of bronchial damage. A shorter distance from the left main bronchus-LSPV might increase the risk of bronchial damage.

\section{Challenges to overcome anatomical difficulty}

In figure 7, we summarised ideas and techniques for overcoming anatomical difficulties in relation to cryoballoon. There are three aspects of difficulties: PV length, PV angle and PV ostium area. We need to solve these problems using procedure-related technique or improvement of device itself. To cope with the problem of PV angle especially RIPV, the anterior side puncture may be better for the access to RIPV (figure 7A-D) ${ }^{29}$ With a puncture at anterior side of atrial septum, we may be able to have enough distance to bend the sheath and cryoballoon from atrial septum to RIPV. However, when we do a septal puncture at anterior side, LSPV may be hard to be isolated. For patients with large inferior PV, 'pull-down' technique is useful (figure 7E,F). ${ }^{29}{ }^{36}$ With the cryoballoon in contact with the superior circumference of the target PV angiographically, freezing of the cryoballoon by $\mathrm{N}_{2} \mathrm{O}$ flow is started. Next, the sheath and frozen cryoballoon in contact with the superior PV circumference are pulled down to close the gap of inferior PV circumference. Thus, full ablation of the target PV circumference can be achieved. ${ }^{37}$ 'Hockey stick' technique is useful for achieving contact of cryoballoon at the inferior PV circumference in patients with an early branching inferior PV. The Achieve catheter (Medtronic) is placed in an early branching inferior PV. The sheath is advanced over the catheter. Passing through the sheath bended, the cryoballoon can achieve contact with the ostium of inferior PV circumference (figure $7 \mathrm{G}$ ). ${ }^{37}$ For patients with no early branch of LSPV, proximal sealing technique is useful (figure 7H,I). First, instead of initiating ablation after initial venogram, the cryoballoon is gently pulled back to reveal the PV ostium by noting contrast leak. Then, the cryoballoon is reapplied to the PV ostium with the minimal amount of pressure to achieve occlusion before ablation. ${ }^{29}$ This technique can lead to misinterpretation of the PV ostium. Care should be taken to not miss the slight contrast leak to avoid freezing of PV circumference at a relative inside. In case of tiny PV or 
A
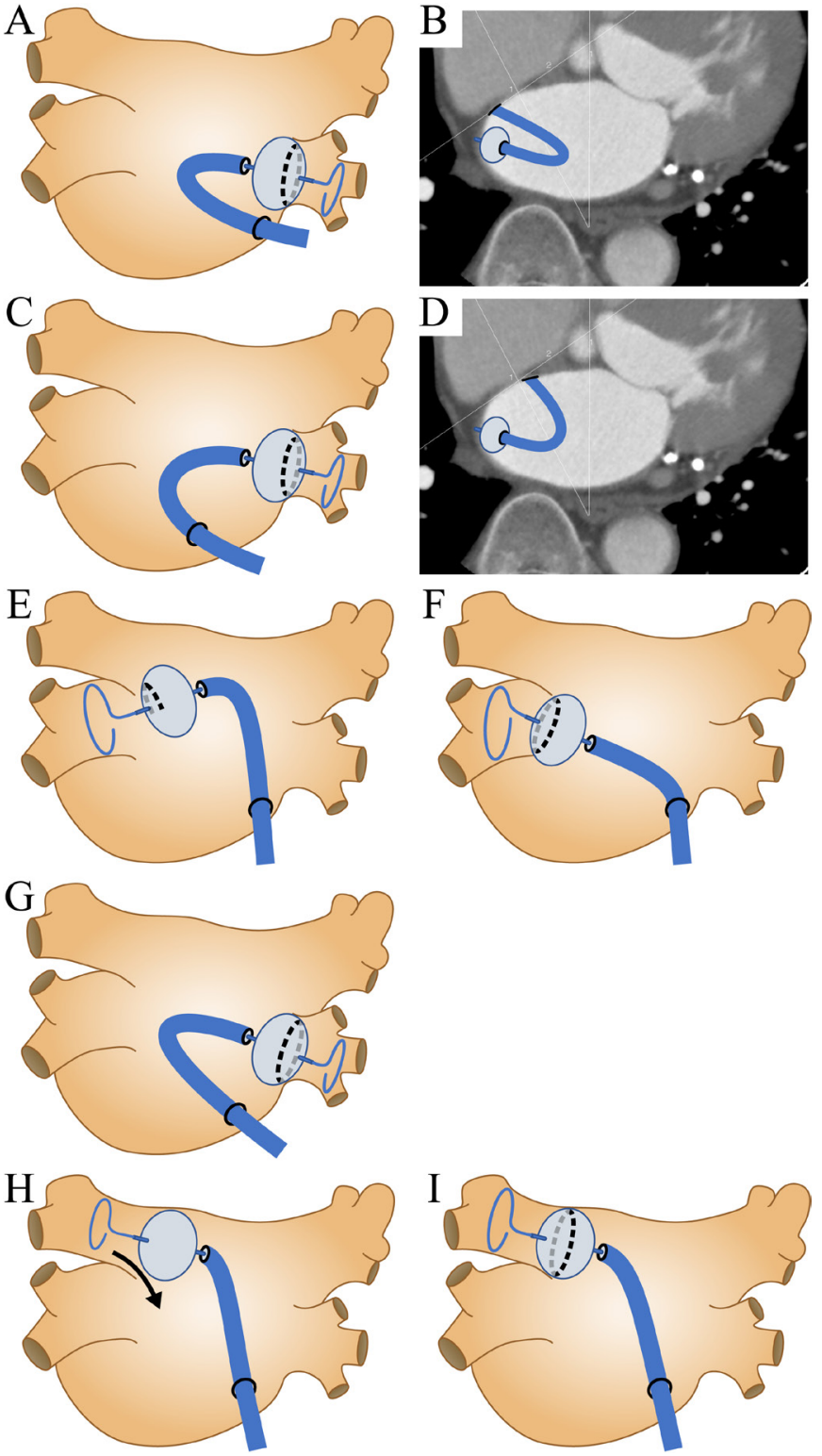

Figure 7 Technical challenges for patients with difficult anatomies. (A) The three-dimensional (3D) image of transseptal puncture at posterior side. (B) The horizontal image of transseptal puncture at posterior side. (C) The 3D image of transseptal puncture at anterior side. (D) The horizontal image of transseptal puncture at anterior side. (E) (F) 'Pullback' technique: cryoballoon is attached to superior part of pulmonary vein (PV) and started to freeze. Then an operator pulls back cryoballoon to inferior part of PV. (G) 'Hockey stick' technique: sheath is advanced with maximal bend, allowing the balloon to be pushed into the PV ostium. (H) (I) Proximal seal technique: first, instead of initiating ablation after initial venogram, the cryoballoon is gently pulled back to reveal the real PV ostium by noting contrast leak. Then, the cryoballoon is reapplied to the PV ostium with the minimal amount of pressure to achieve occlusion before ablation.

as a bailout strategy in case of difficult anatomies, the smaller $23 \mathrm{~mm}$ cryoballoon in diameter is reported to be useful to achieve PV isolation. ${ }^{38}$
Safety measures should be considered to avoid complications shown in table 4 . To prevent phrenic nerve palsy during ablation, monitoring diaphragmatic compound motor action potentials (CMAP) is helpful. There are several methods for phrenic nerve monitoring strategies such as fluoroscopy, palpation, electromyography, auditory cardiotocography and intracardiac echocardiography (ICE). ${ }^{39}$ Fluoroscopy and ICE are useful to directly see diaphragmatic motion. Using electromyography, operators can detect reduction of the amplitude of CMAP during procedure. In previous study, 30\% reduction in the amplitude of CMAP was reported as the most predictive cut-off value for hemidiaphragmatic paralysis. ${ }^{40}$ As for oesophageal injury, monitoring oesophageal temperature may be helpful. Cryoballoon nadir ablation temperate above $-55^{\circ} \mathrm{C}$ is appropriate. ${ }^{29}$ Based on the comparison between the lowest oesophageal temperature and the endoscopic finding, Metzner et al recommend that a cut-off value of oesophageal temperature is $10^{\circ} \mathrm{C}$ (sensitivity $100 \%$, specificity $93 \%$ ), and Fürnkranz et al suggest that a cut-off value is $12^{\circ} \mathrm{C}$ (sensitivity $100 \%$, specificity $92 \%$ ) to induce oesophageal injury. ${ }^{28}{ }^{41}$ Monitoring oesophageal temperature using a probe may be helpful to avoid oesophageal injury during cryoballoon ablation. As to PV stenosis, ablation of PV circumference at a relative inside might be a predictor. ${ }^{42}$ Careful examination of the venogram should be done to not miss the slight contrast leak. For patients requiring reduction of fluoroscopy time or contrast, ICE and trans-oesophageal echocardiography are reported to be useful to check leak of blood or saline from PV to atrium. ${ }^{434}$ There is a report that transcatheter pressure inside PV can be monitored during balloon advancement. Verification of PV occlusive pressure during cryoballoon ablation is one of the indicators to confirm proper PV occlusion. ${ }^{45}$ We summarised procedural techniques and safety measures which should be considered when physicians encounter difficult anatomies of PV-LA (figure 8).

\section{Other modalities}

CT is a powerful tool to identify PV anatomy, location of phrenic nerve and oesophagus. However, radiation exposure could be a concern. There was a case report of fluoroscopy-free cryoablation with trans-oesophageal echocardiography. ${ }^{44}$ Three-dimensional mapping system, ICE and trans-oesophageal echocardiography may assist reducing fluoroscopic time.

\section{Limitations}

First, all studies were single-centre studies, and most of the predictors discussed in each study varied. Multicentre studies should be conducted to further quantify the thresholds of each predictor. An investigation using a unified and easier measurement definition should be used to further investigate the proper treatment of patients with AF using cryoballoon. Second, all the studies were observational with retrospective analysis of the CT anatomy. Third, it was not clear if the CT was 


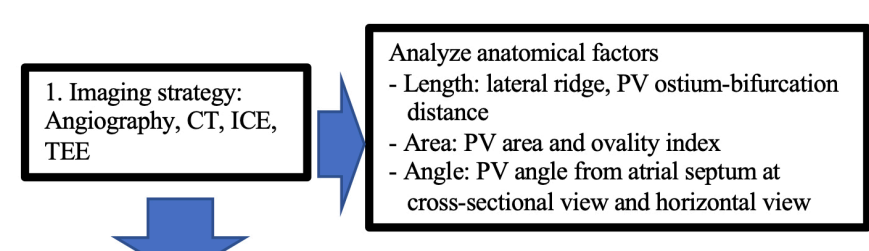

2. Location of septal puncture: anterior side or posterior side

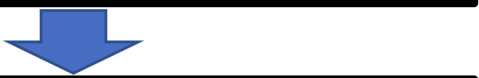

3. If $\mathrm{PV}$ is not isolated, several techniques should be considered.

- Pull-down technique for patients with large inferior PV

- Proximal sealing technique for patients with no early branch of LSPV

- Hockey-stick technique for patients with an early branching inferior PV

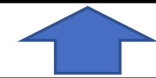

4. To avoid complications, the followings should be considered

- Use esophageal temperature probe with certain cut off

- Monitor diaphragmatic compound motor action potentials

- Be careful not to freeze PV circumferences at a relative inside to avoid

$\mathrm{PV}$ stenosis especially in large PV in angiography, or verify antral position by ICE or TEE

Figure 8 A flow chart for treating patients with $\mathrm{AF}$ using cryoballoon. How to cope with anatomical challenges while ensuring safety. ICE, intracardiac echocardiography; LSPV, left superior pulmonary vein; PV, pulmonary vein; TEE, transoesophageal echocardiography.

available/integrated into the X-ray system as a full threedimensional reconstruction in each study. Forth, it was not clear if patients were selected for cryoballoon ablation with/without CT examination before. Fifth, there is a major risk for operators' or institutional bias. We could not identify from the articles if published data showed their initial experience with cryoballoon ablation and might include physician's learning curves.

\section{CONCLUSION}

This study elucidated several key anatomical features of PVs that might affect acute success, AF recurrence and complications in patients with AF using cryoballoon ablation. CT analysis has helped to describe benefits and limitations for cryoballoon ablation in terms of anatomy. To better treat patients with AF with difficult anatomies, technical challenges presented in this study should be overcome.

Acknowledgements The authors are deeply grateful to the radiological technologists at Shonan Kamakura General Hospital.

Contributors TH: design, data collection, analysed data, interpretation, writing original draft. Kl: concept, design, data collection, interpretation, critical revision of article, supervision, the guarantor of the paper. MM: data collection, interpretation. SS: data collection, interpretation.

Funding This study was supported in part by a research project at Institute for Medical Regulatory Science, Comprehensive Research Organization, Waseda University.

Competing interests None declared.

Patient consent for publication Consent obtained from next of kin.

Ethics approval This study does not involve human participants.
Provenance and peer review Not commissioned; externally peer reviewed.

Data availability statement Data sharing not applicable as no datasets generated and/or analysed for this study.

Open access This is an open access article distributed in accordance with the Creative Commons Attribution Non Commercial (CC BY-NC 4.0) license, which permits others to distribute, remix, adapt, build upon this work non-commercially, and license their derivative works on different terms, provided the original work is properly cited, appropriate credit is given, any changes made indicated, and the use is non-commercial. See: http://creativecommons.org/licenses/by-nc/4.0/.

ORCID iD

Takahiro Hayashi http://orcid.org/0000-0003-0398-858X

\section{REFERENCES}

1 January CT, Wann LS, Alpert JS, et al. 2014 AHA/ACC/HRS guideline for the management of patients with atrial fibrillation: a report of the American College of Cardiology/American heart association Task force on practice guidelines and the heart rhythm Society. J Am Coll Cardiol 2014:64:e1-76.

2 Haïssaguerre M, Jaïs P, Shah DC, et al. Spontaneous initiation of atrial fibrillation by ectopic beats originating in the pulmonary veins. N Engl J Med 1998;339:659-66.

3 Packer DL, Kowal RC, Wheelan KR, et al. Cryoballoon ablation of pulmonary veins for paroxysmal atrial fibrillation: first results of the North American Arctic front (stop AF) pivotal trial. J Am Coll Cardiol 2013;61:1713-23.

4 Schmidt M, Dorwarth UWE, Andresen D, et al. Cryoballoon versus if ablation in paroxysmal atrial fibrillation: results from the German ablation registry. J Cardiovasc Electrophysiol 2014;25:1-7.

5 Kuck K-H, Brugada J, Fürnkranz A, et al. Cryoballoon or radiofrequency ablation for paroxysmal atrial fibrillation. $N$ Engl $J$ Med 2016;374:2235-45.

6 Knight BP, Novak PG, Sangrigoli R, et al. Long-Term outcomes after ablation for paroxysmal atrial fibrillation using the second-generation Cryoballoon: final results from stop AF Post-Approval study. JACC Clin Electrophysiol 2019;5:306-14.

7 Kajiyama T, Miyazaki S, Matsuda J, et al. Anatomic Parameters Predicting Procedural Difficulty and Balloon Temperature Predicting Successful Applications in Individual Pulmonary Veins During 28-mm Second-Generation Cryoballoon Ablation. JACC Clin Electrophysiol 2017;3:580-8.

8 Yasuoka R, Kurita T, Kotake Y, et al. Particular morphology of inferior pulmonary veins and difficulty of Cryoballoon ablation in patients with paroxysmal atrial fibrillation. Circ J 2017;81:668-74.

9 Matsumoto Y, Muraoka Y, Funama Y, et al. Analysis of the anatomical features of pulmonary veins on pre-procedural cardiac CT images resulting in incomplete cryoballoon ablation for atrial fibrillation. $J$ Cardiovasc Comput Tomogr 2019;13:118-27.

10 Kocyigit D, Yalcin MU, Gurses KM, et al. Pulmonary vein orientation is independently associated with outcomes following cryoballoonbased atrial fibrillation ablation. $J$ Cardiovasc Comput Tomogr 2018;12:281-5

11 Güler E, Güler GB, Demir GG, et al. Effect of pulmonary vein anatomy and pulmonary vein diameters on outcome of Cryoballoon catheter ablation for atrial fibrillation. Pacing Clin Electrophysiol 2015;38:989-96.

12 Terasawa M, Chierchia Gian-Battista, Takarada K, et al. Anatomic predictors of late right inferior pulmonary vein reconnection in the setting of second-generation cryoballoon ablation. $J$ Cardiovasc Electrophysiol 2019;30:2294-301.

13 Vaishnav AS, Alderwish E, Coleman KM, et al. Anatomic predictors of recurrence after cryoablation for atrial fibrillation: a computed tomography based composite score. J Interv Card Electrophysiol 2021;61:293-302.

14 Mulder BA, Al-Jazairi MIH, Arends BKO, et al. Pulmonary vein anatomy addressed by computed tomography and relation to success of second-generation cryoballoon ablation in paroxysmal atrial fibrillation. Clin Cardiol 2019;42:438-43.

15 Ichihara N, Miyazaki S, Iwasawa J, et al. Prevalence and PreProcedural Predictors Associated With Right Phrenic Nerve Injury in Electromyography-Guided, Second-Generation Cryoballoon Ablation: Single Large Balloon and Single 3-Minute Freeze Techniques. JACC Clin Electrophysiol 2016;2:508-14.

16 Ströker E, de Asmundis C, Saitoh Y, et al. Anatomic predictors of phrenic nerve injury in the setting of pulmonary vein isolation using the 28-mm second-generation cryoballoon. Heart Rhythm 2016;13:342-51. 
17 Maj R, Borio G, Ströker E, et al. Phrenic nerve palsy during right-sided pulmonary veins cryoapplications: new insights from pulmonary vein anatomy addressed by computed tomography. $J$ Interv Card Electrophysiol 2021;60:85-92.

18 Miyazaki S, Nakamura H, Taniguchi H, et al. Esophagus-Related complications during second-generation Cryoballoon AblationInsight from simultaneous esophageal temperature monitoring from 2 esophageal probes. J Cardiovasc Electrophysiol 2016;27:1038-44.

19 Matsumoto Y, Kaneshiro T, Hijioka N, et al. Predicting factors of transmural thermal injury after cryoballoon pulmonary vein isolation. J Interv Card Electrophysiol 2019;54:101-8.

20 Coutiño H-E, Takarada K, Sieira J, et al. Anatomical and procedural predictors of pulmonary vein stenosis in the setting of secondgeneration cryoballoon ablation. J Cardiovasc Med 2018;19:290-6.

21 Narui R, Tokuda M, Matsushima M, et al. Incidence and factors associated with the occurrence of pulmonary vein narrowing after Cryoballoon ablation. Circ Arrhythm Electrophysiol 2017;10:e004588.

22 Wei H-Q, Guo X-G, Zhou G-B, et al. Predictors of hemoptysis in the setting of pulmonary vein isolation using the second-generation cryoballoon. J Cardiovasc Electrophysiol 2018;29:958-65.

23 Heeger C-H, Wissner E, Mathew S, et al. Once isolated, always isolated? incidence and characteristics of pulmonary vein Reconduction after second-generation CryoballoonBased pulmonary vein isolation. Circ Arrhythm Electrophysiol 2015;8:1088-94.

24 Koektuerk B, Yorgun H, Koektuerk O, et al. Characterization of electrical reconnection following pulmonary vein isolation using first- and second-generation Cryoballoon. Pacing and Clinical Electrophysiology 2016;39:434-42.

25 Heeger C-H, Rexha E, Maack S, et al. Reconduction After SecondGeneration Cryoballoon-Based Pulmonary Vein Isolation - Impact of Different Ablation Strategies —. Circ J 2020;84:902-10.

26 Matsumoto Y, Krishnan S, Fowler SJ, et al. Detection of phrenic nerves and their relation to cardiac anatomy using 64-slice multidetector computed tomography. Am J Cardiol 2007;100:133-7.

27 Sánchez-Quintana D, Cabrera José Angel, Climent V, et al. Anatomic relations between the esophagus and left atrium and relevance for ablation of atrial fibrillation. Circulation 2005;112:1400-5.

28 Metzner A, Burchard A, Wohlmuth P, et al. Increased incidence of esophageal thermal lesions using the second-generation $28-\mathrm{mm}$ cryoballoon. Circ Arrhythm Electrophysiol 2013;6:769-75.

29 Su W, Kowal R, Kowalski M, et al. Best practice guide for cryoballoon ablation in atrial fibrillation: the compilation experience of more than 3000 procedures. Heart Rhythm 2015;12:1658-66.

30 Tokutake K, Tokuda M, Yamashita S, et al. Anatomical and procedural factors of severe pulmonary vein stenosis after Cryoballoon pulmonary vein ablation. JACC Clin Electrophysio 2019;5:1303-15
31 Avitall B, Kalinski A. Cryotherapy of cardiac arrhythmia: from basic science to the bedside. Heart Rhythm 2015;12:2195-203.

32 Verma N, Gillespie CT, Argento AC, et al. Bronchial effects of cryoballoon ablation for atrial fibrillation. Heart Rhythm 2017;14:12-16.

33 van Opstal JM, Timmermans C, Blaauw Y, et al. Bronchial erosion and hemoptysis after pulmonary vein isolation by cryoballoon ablation. Heart Rhythm 2011;8:1459.

34 Bhagwandien R, Van Belle Y, de Groot N, et al. Hemoptysis after pulmonary vein isolation with a cryoballoon: an analysis of the potential etiology. J Cardiovasc Electrophysiol 2011;22:1067-9.

35 Kumar N, Timmermans C, Das M, et al. Hemoptysis after cryoablation for atrial fibrillation: truth or just a myth? Chest 2014;146:e173-5.

36 Baszko A, Kałmucki P, Dankowski R, et al. Transseptal puncture from the jugular vein and balloon cryoablation for atrial fibrillation in a patient with azygos continuation of an interrupted inferior vena cava. Europace 2015;17:1153-6.

37 Chun K-RJ, Schmidt B, Metzner A, et al. The 'single big cryoballoon technique for acute pulmonary vein isolation in patients with paroxysmal atrial fibrillation: a prospective observational single centre study. Eur Heart J 2009;30:699-709.

38 Hartl S, Dorwarth U, Bunz B, et al. Lessons from individualized cryoballoon sizing. is there a role for the small balloon? J Cardiol 2017;70:374-81.

39 Kowalski M, Ellenbogen KA, Koneru JN. Prevention of phrenic nerve injury during interventional electrophysiologic procedures. Heart Rhythm 2014:11:1839-44.

40 Franceschi F, Dubuc M, Guerra PG, et al. Diaphragmatic electromyography during cryoballoon ablation: a novel concept in the prevention of phrenic nerve palsy. Heart Rhythm 2011;8:885-91.

41 Fürnkranz A, Bordignon S, Schmidt B, et al. Luminal esophageal temperature predicts esophageal lesions after second-generation cryoballoon pulmonary vein isolation. Heart Rhythm 2013;10:789-93.

42 Holmes DR, Monahan KH, Packer D. Pulmonary vein stenosis complicating ablation for atrial fibrillation: clinical spectrum and interventional considerations. JACC Cardiovasc Interv 2009;2:267-76

43 Kanda T, Masuda M, Kurata N, et al. A saline contrast-enhanced echocardiography-guided approach to cryoballoon ablation. Pacing Clin Electrophysiol 2020;43:664-70.

44 Balmforth DC, Smith A, Schilling R, et al. Fluoroscopy-free cryoablation of atrial fibrillation guided solely by transoesophageal echocardiography: a case report. Eur Heart J Case Rep 2018;2:yty137.

45 Kosmidou I, Wooden S, Jones B, et al. Direct pressure monitoring accurately predicts pulmonary vein occlusion during cryoballoon ablation. J Vis Exp 2013:e50247. 